Edith Cowan University

Research Online

Research outputs 2012

$1-1-2012$

\title{
To what extent do wineries study their consumers and visitors? Implications for wine tourism development
}

\author{
Abel Alonso \\ Alessandro Bressan \\ Michelle O'Shea \\ Vlad Krajsic
}

Follow this and additional works at: https://ro.ecu.edu.au/ecuworks2012

Part of the Business Commons

10.3727/108354212X13485873914001

This is an Author's Accepted Manuscript of: Alonso, A. D., Bressan, A., O'Shea, M., \& Krajsic, V. (2012). To what extent do wineries study their consumers and visitors? Implications for wine tourism development. Tourism Analysis, 17(5), 643-657. Available here This Journal Article is posted at Research Online. https://ro.ecu.edu.au/ecuworks2012/493 


\section{CONTENTS}

Measuring the Economic Impact of Migration-Induced Tourism

Peter Forsyth, Larry Dwyer, Neelu Seetaram, and Brian King

The Impact of TV Drama Attributes on Touristic Experiences at Film Tourism Destinations Sangkyun (Sean) Kim

Examining a Supply-Side Predictive Model in Tourism Using Partial Least Squares Path Modeling: An Empirical Analysis at the Country Aggregate Level Guy Assaker and Rob Hallak

Second-Home Ownership and Place Attachment: Drivers of Visitation, Word-of-Mouth Promotion, and Hosting

Brumby McLeod and James A. Busser

Experience Quality in the Different Phases of a Tourist Vacation: A Case Study of Northern Norway Nina K. Prebensen, Eunju Woo, Joseph S. Chen, and Muzaffer Uysal

Organizational-Level RFID Technology Adoption in the Hospitality Industry Ahmet Bulent Ozturk, Radesh Palakurthi, and Murat Hancer

To What Extent Do Wineries Study Their Consumers and Visitors? Implications for Wine Tourism Development

Abel Duarte Alonso, Alessandro Bressan, Michelle O'Shea, and Vlad Krajsic

Casino Development and Visitor Satisfaction: A Case of Korea

Woo-Hee Byun, Bon-Ki Koo, and Timothy. Jeonglyeol Lee

\section{RESEARCH NOTES}

Eilat Syndrome: Deviant Behavior Among Temporary Hotel Workers Yaniv Belhassen

Applications of Partial Least Squares Structural Equation Modeling in Tourism Research:

A Methodological Review

Guy Assaker, Songshan (Sam) Huang, and Rob Hallak

\section{BOOK REVIEW}

Polar Tourism: Human, Environmental and Governance Dimensions (Patrick Maher, Emma Stewart, and Michael Lück) 


\title{
TO WHAT EXTENT DO WINERIES STUDY THEIR CONSUMERS AND VISITORS? IMPLICATIONS FOR WINE TOURISM DEVELOPMENT
}

\author{
ABEL DUARTE ALONSO, *† ALESSANDRO BRESSAN,* \\ MICHELLE O'SHEA,* AND VLAD KRAJSIC**
}

*School of Business, University of Western Sydney, Penrith South DC, NSW, Australia $\nmid$ School of Marketing, Tourism and Leisure, Edith Cowan University, Western Australia

\begin{abstract}
In their quest for long-term sustainability and financial success, winery entrepreneurs increasingly perceive wine tourism and tourism-related enterprises as important facets of their business strategy. However, to benefit from wine tourism activities, winery operators will need to develop new skills and business capabilities. In this context, learning from and understanding consumers and visitors' preferences and expectations is of paramount importance to wineries' long-term sustainability and, importantly, their financial success. This study examines the extent to which winety owners and managers "study" their visitors, gathering data from 451 Italian, Spanish, and New World small and medium wineries. The majority of respondents indicate studying visitors to some extent; however, one third do not actively engage in activities that enable them to learn about visitor preferences and experiences, while over $40 \%$ would like to learn more about them. In addition, while respondents generally perceive studying visitors as beneficial, others are either skeptical or consider their current efforts sufficient. At a time when consumers have numerous leisure choices available to them, wineries and wine labels are operating in a highly competitive and increasingly sophisticated environment, these findings have significant implications for wine tourism specifically, as well as the hospitality and wine sectors generally.
\end{abstract}

Key words: Wine sector; Wine tourism; Winery consumers and visitors (CsVs); Wineries; Study of visitors; Old World; New World

Introduction

The "natural" links between grapes and wine and rural areas, landscape, and hedonic experiences also extend to their strong association with the wine industry, tourism, and hospitality. These associations and synergies unite these sectors, and include activities ranging from wine consumption, food and wine pairings, and overall added value of the consumption experience. In the last two decades, there has been a well-documented interest and popularity in "wine tourism" among practitioners (wineries), researchers, and consumers. Several authors (Hall, Sharples, Camboume, \& Macionis, 2000;

Address correspondence to Abel Duarte Alonso, Ph.D., Researclier and Lecturer, University of Western Sydney, School of Business, Locked Bag 1797, Penrith South DC, NSW 2571, Australia. Tel: (02)-9685-9436; Fax: (02)-9685-9593;

E-mail: a.duartealonso@uws.edu.au 
O'Neill, Palmer, \& Charters, 2002) refer to wine tourism as an activity that essentially involves visitation of wineries to learn about wines, to taste wines, meet the wine makers, enjoy the scenery, and, whenever available, accompany wineries' wine product with local foods.

Within the wine tourism experience, cellar door visits are one of the highlights (Alant \& Bruwer, 2004; Hall et al., 2000; Macionis \& Camboume, 1998), in part because these spaces represent a "unique consumption setting" (Gill, Byslma, \& Ouschan, 2007, p. 257). The proximity of many cellar doors to the wineries' vineyards or winemaking facilities also serves to reinforce the educational aspects of the winery visit. Moreover, a cellar door's more intimate setting, as opposed to the "faceless" supermarket or liquor store environment, can also enhance the potential for initiating winery-consumer relationships in various forms. Gill et al. (2007) use the term "public face of the winery" (p. 257) to further underline the symbolic but vital importance of the cellar door. Indeed, these authors conclude that the cellar door is particularly important for small wineries as it may be their "largest distribution channel available" (p. 258). Hence, providing more personalized winery experiences, coupled with educational efforts to create winery-visitor relationships, and continuously monitoring consumer behavior (visitors' winery experience) could provide both tangible and intangible benefits to winery businesses and their surrounding communities.

In this context, Asero and Patti (2011, p. 443) explain that research conducted on wine tourists' behavior can be helpful in the development of wine tourism, as well as assisting wineries in managing wine tourist demand. Many studies have sought to gain an understanding of winery visitors, often referred to as "wine tourists." Researchers have investigated winery experiences in terms of demographic and psychographic characteristics (Tassiopoulos, Nuntsu, \& Haydam, 2004), purpose of visit (Charters \& Ali-Knight, 2002), service quality at the cellar door (O'Neill \& Charters, 2000), and wine tourism destination image attributes (Williams, 2001).

Despite the value and contribution of these studies, several areas concerning the winery experience remain underresearched. One research gap relates to the strategies wineries are utilizing to understand the motivations and preferences of their current and potential visitors. Examining this critical wineryvisitor dimension could be useful for individual wineries, their regional and national wine sectors, as well as for other "stakeholders," including visitors, the hospitality sector, rural areas, and their communities. Additionally, in times of economic uncertainty and struggle among rural communities, new and added information could enable wineries and their host communities to better position themselves as valid and "attractive" tourism and culinary destinations. Therefore, the present study sheds light on areas in which wineries could positively impact their marketing and service and product quality performance efforts, particularly concerning their visitors. The following research questions (RQs) are proposed and investigated:

RQ1: To what extent do winery operators (their owners and managerș) as part of their business strategies "study" their consumers, including visitors to their wineries?

RQ2: In what ways, if any, do wineries' management seek to learn about their visitors' winery experience, or gather feedback from them?

RQ3: What are their interpretations of the perceived and actual benefits of studying their visitors?

The study will predominantly focus on small and nicrowineries, as these enterprises represent the majority in their sector in most wine-producing countries (O'Neill \& Palmer, 2004), and therefore represent an important group.

\section{Literature Review}

Importance of Consumer Research in the Wine Sector

The wine sector is a key element in the culture and tradition of many rural regions. Wineries and their allied business constitute an important economic engine. For example, in many cases wineries can be an important source of employment, or contribute to ensuring individuals' livelihood, and in turn add to the material prosperity of the rural communities in which they live. Additionally, and indirectly, wineries and vineyards can add "scenic value" to a region (Scherrer, Alonso, \& Sheridan, 
2009), especially to travelers' enjoyment, and potentially contribute to economic and noneconomic "multiplier effects" derived from tourism development.

In recent years, and partly following the developments of numerous New World regions (e.g., Napa and Sonoma Valley, California; Hunter Valley, Australia; Marlborough, New Zealand), several Old World wine regions (e.g., Tuscany, Rioja, Bordeaux) have increased their involvement in developing wine tourism. Arguably, wine tourism is already well established in some old World regions (O'Neill \& Palmer, 2004). However, recent studies (Alonso \& Lill, 201 1; Asero \& Patti, 2011; LópezGuzmán, Rodríguez-García, Sánchez-Cañizares, \& Luján-García, 2011; Marzo-Navarro \& PedrajaIglesias, 2012) suggest that in other European regions it remains underdeveloped.

As a result of government, regional, and other initiatives, wine trails are being established to cater for and encourage wine tourism. In spite of government and regional initiatives, individual entrepreneurial efforts among wineries willing to join the "wine tourism bandwagon" appear to be more conmon. In opening one's doors to the public, creating visitor-winery relationships, drawing visitors to rural areas and ultimately marketing a local product (wine), studying one's consumers, and educating visitors could become vital tools for winery entrepreneurs. For many wine consumers, including nontraditional consumers ("beginners"), and those interested in knowing about wines, wineries and their cellar doors can contribute to increased wine knowledge, generally in a nonthreatening environment (Dodd, 1995).

The creation of nonthreatening, welcoming cellar door environments could be valuable to winery operators' market expansion strategies. For example, authors including Alonso (201 la) and Gluckman (1986) have reflected on the snobbery and pretense often associated with wine products, and explained that this snobbery could potentially disenfranchise a nontraditional consumer marketplace. The intimidation factor is also evident in that many wine consumers lack confidence when it comes to wine selection, either when choosing wine for themselves or to share with others (LaTour, LaTour, \& Feinstein, 2011, p. 445). The fact that many micro, small, and medium wine producers heavily depend on sales through their cellar doors (Carlsen, 2004) reinforces the importance of these environments in spreading wine knowledge, studying visitors, improving the image that wines have among some consumers (i.e., its links with "snobbery"), and building strong winery-visitor relationships.

According to O'Neill et al. (2002, p. 342), developing reliable and simple measurements of service quality is a critical component in consumer behavior and services marketing research. O'Neill et al. (2002) refer to the winery visit part of both "tangible and service production processes" (p. 342), thus suggesting the importance of the wine product, as well as that of the "human touch" in the winery or cellar door experience. Together, these elements can add the extra value that wine purchases in other environments may not provide. From the demand side (consumers and visitors, from here onwards abbreviated as "CsVs") service quality, technical quality (e.g., wine quality), price, and "social value" can have a positive impact on winery visitors (Gill et al., 2007). Further, from a supply point of view, O'Neill and Palmer (2004, p. 273) note three clear opportunities for winery owners to tap into, namely: the chance to add value to the winery, minimize distribution costs, and develop brand equity. Further, Bruwer (2003) explains the benefit (supply side) from understanding cellar door visitors in terms of developing "more appropriate and improved wine tourism products" (p. 424).

Regarding the concept of wine tourism, Carlsen (2004) cautions that "most visits to wineries are only part of an overall holiday" (p. 7), and that "it may be premature to develop specific marketing strategies for wine tourists" (p. 7). However, wine tourism involvement is indeed diverse, and not only refers to traveling through a wine region, but also the simple act of stopping at the winery to purchase wines (Alant \& Bruwer, 2004). Moreover, the development and establishment of wine routes, or simply the location of many wineries open to the public near cities, or in and around tourist destinations such as the cases of New Zealand (Marlborough, Wairarapa), Australia (Hunter Valley, Swan Valley), Italy (Tuscany) or California (Napa Valley) illustrate that individual visitation and discovery are possible.

An "impromptu" stop at a winery to purchase wines and a resulting positive cellar door experience 
could lead to individuals seeking the local brand (if available) elsewhere, spreading positive word of mouth about the winery (O'Neill \& Palmer, 2004), physically traveling to the region again, or bringing new visitors. When discussing the "life stage" dimension as it relates to wine tourism, Brown and Getz (2005) refer in part to this aspect when they underline the importance of "the presence of a "significant other' who is also a wine lover" (p. 268) as a way to facilitate wine tourism involvement. Other forms of tourism can be encouraged, because some wine regions possess attributes that provide a range of "experience options for wine tourists" (Alant \& Bruwer, 2004, p. 28). In fact, Brown and Getz (2005) noticed in some wine regions that respondents were traveling "for reasons other than wine" (p. 275), even though "where possible, they included wine in their activities" (p. 275), thus taking advantage of being in a wine region.

Consequently, Brown and Getz (2005) suggest that both wine exports and wine tourism "should be mutually reinforcing" (p. 267), further strengthening the argument that wine tourism's potential, benefits, and ramifications can transcend beyond the winery surroundings or postpurchase behavior. Brown and Getz (2005) also associate wine tourism to destination choice theory. They present a framework (wine-related factors in the destination choice model) adapted from Ryan (2002), and partly based on Maslow's hierarchy of needs. Under the item "tourist variables," the framework includes motives, personality, lifestyle, life stage, and experience to increase the understanding of visitors' motivations, which in turn may illuminate the reasons for their product and experience choices. Other contributions of Brown and Getz's (2005) framework include "marketing variables and destination awareness," "affective association to destinations," "tourist destination preferences," and "situational variables" (p. 268). Their findings confirm that personal dimension in the form of tourist variables (needs, motives, personality, lifestyle, experience, and life stage) appeared to be most important to their participants.

Overall, much of the contemporary hospitality and tourism research conducted in wineries focuses on the demand side (CsVs), with studies investigating visitors' winery experiences, including their motivations to visit wineries, or at the cellar door
(Getz \& Brown, 2006). Figure 1 provides a summary of significant elements and themes related to wine tourism's demand (winery visitor). This summary is based on the contemporary wine consumer and wine tourism literature that essentially discusses the multiple benefits that the study of winery visitors may subsequently provide to different stakeholders of the wine and wine tourism equations (e.g., wineries, wine sector).

Despite an ever-growing volume of wine tourism research, many knowledge gaps still exist. According to Carlsen (2004), even the dimension of visitors' motivations to visit wineries has not been sufficiently addressed, but "is yet to be fully developed" (p. 10). Recently, Bruwer, Lesschaeve, and Campbell (2012) argue that "The question 'who is the wine tourist?' has yet to be definitively answered" (p. 46). Moreover, few studies focus on the supply side (winery owners and managers). In particular, very few identify how managers are involved in "studying" their visitors. Given the different implications of this area for wineries, consumers, the hospitality sector, and wine tourism, the present study will seek to shed light on this underresearched area.

\section{Methodology}

Apart from investigating the extent to which wineries study their CsVs, the present exploratory study was part of a larger project that examined facets of winery entrepreneurship, and emergent issues that respondents' businesses and the wine sector as a whole may be facing. More specifically, the project was divided into different themes, including internationalization efforts among wineries, challenges wineries face in the current economic and competitive climate, ways in which the wine sector could be improved, and the extent to which wineries may have benefited from wine tourism. While significant in their own right, these themes are beyond the scope of the present study, and might be addressed in future investigations.

The distant and scattered nature of Italian, Spanish and New World wineries, as well as budget and time constrains prevented the researchers from traveling to all selected nations. Alternative approaches, such as making long-distance telephone calls to interview potential respondents, or 


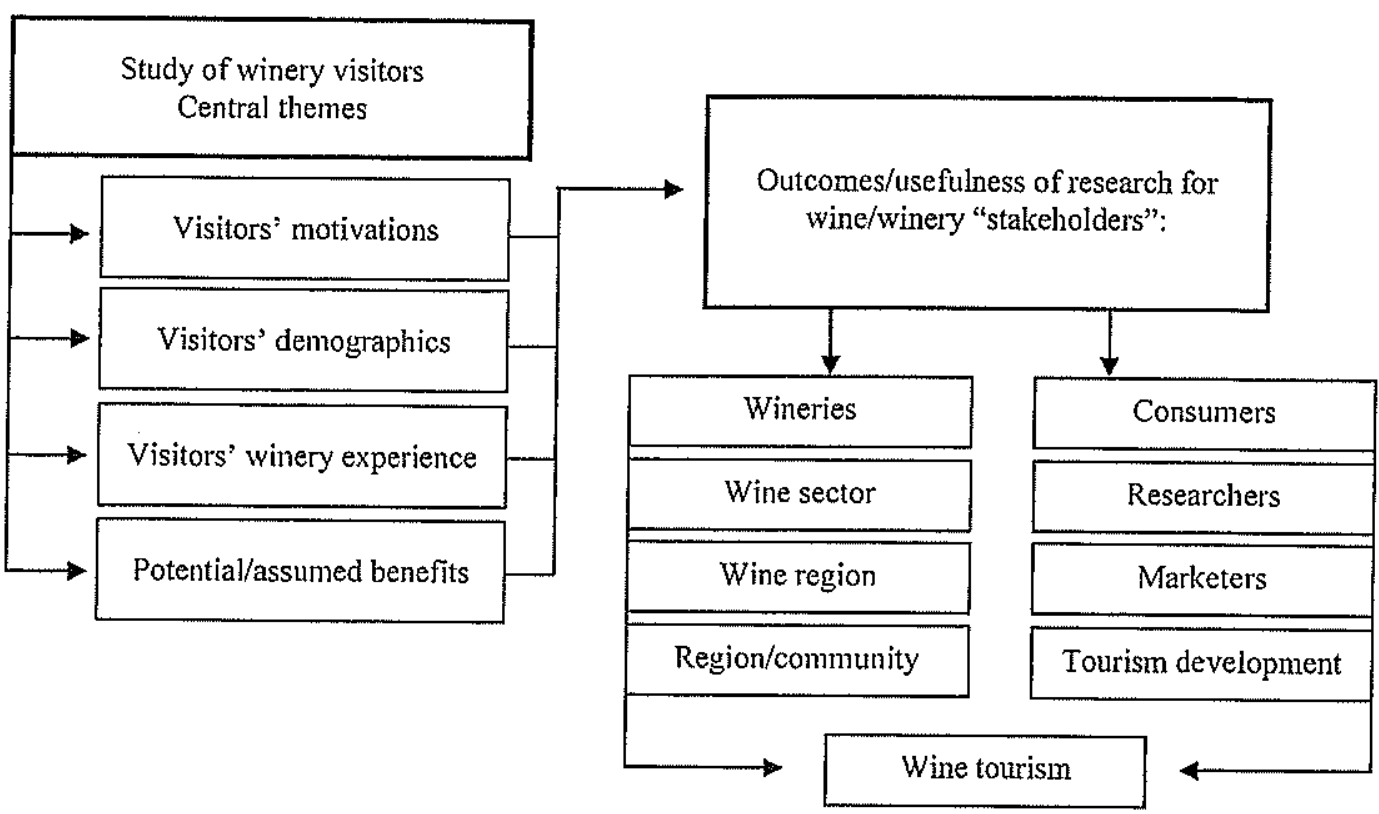

Figure 1. Importance of studying winery visitors. A simplified perspective drawn from contemporary research.

mailing questionnaires overseas were not feasible and, while considered, were not chosen. Instead, to collect data economically, promptly, and conveniently, a decision was made to use an online questionnaire.

Contemporary wine entrepreneurship and wine consumer and wine tourism research was consulted when developing the survey instrument (e.g., AliKnight \& Charters, 1999; Alonso, 2011b; O'Neill \& Palmer, 2004; O'Neill et al., 2002). As noted, in this study the overarching theme-and therefore the research questions-were concerned with the extent to which wineries study their visitors. Thus, apart from providing space available in the form of comment boxes to gather their views (qualitative data) regarding the research questions, a decision was made to provide respondents with several answer choices that might address these questions. For instance, the options respondents could select from (i.e., "check" the response choice in the online questionnaire as applicable) sought to learn about their proactive efforts, particularly in answering the following overarching question: To what extent does your winery 'study' wine consumers, for instance, people visiting your winery? The available choices were:
Sometimes we talk to our visitors, for instance, to gather their views on our wines.

Sometimes we carry out surveys among our consumers (for instance, via questionnaires).

We are interested in learning more about our consumers.

In addition, based on one of the authors' previous observations and research experience, it was also determined to provide other choices that may illustrate wineries' limitations in studying their CsVs. Thus, the following statements or answer choices were available for respondents to select ("check" in the online questionnaire) as applicable:

We do not have the means (economic, human, other) to study our consumers.

We do not carry out any study about our consumers at this point.

We do not believe that studying our consumers is necessary.

We do not have time to study our consumers.

Between February and June of 2011, all wine regions (designations of origin or DOs) of Italy and Spain were consulted using regional, DO, and national websites. In the case of New World 
wineries, websites of local winery listings and national wine associations were used. All the wineries that featured an electronic mail (email) as part of their contact details were chosen; subsequently, a database of all existing email addresses was created. A message sent to the attention of wineries' management explained the purpose of the study, its objectives, and potential benefits, and invited recipients to participate in the study using a link to the online questionnaire provided in the message. As Table 1 indicates, a total of 7,192 wineries were contacted; each message was sent to small groups of wineries (between three and seven addresses each time). A reminder was sent approximately 10 days after the first contact, followed by a last reminder with a "thank you" message.

Given that the study focused on small (micro) and medium enterprises (SMEs), a decision was made to include all wineries that employed 30 or fewer full-time employees. Thus, the study uses a subset of the entire sample, or $88.8 \%(451 / 508) ; 55$ respondents indicated employing more than 30 full-time employees, and two did not indicate their number of full-time employees. In addition, there was concern that, if included, this small number of wineries excluded (57) might contribute to the skewing of some of the results. Overall, given the much larger ratio of SMEs in the study (451 vs. $57)$, it was decided to use this number as the final subset. Review of the literature identified that definitions of SMEs differ internationally. For instance, in New Zealand, SMEs employ fewer than 20 employees (Ministry of Economic Development, 2005), in Australia fewer than 200 (Australian Bureau of Statistics 2001), and in European Union nations 250 or fewer (European Commission, 2010). Because no universal SME definition exists, the selection of 30 and fewer full-time employees was deemed appropriate. Under this selection protocol, 451 usable responses were obtained (Table 1). Arguably, many among the 7,192 wineries contacted may be considered medium or large in size. However, the number of responses in this study is calculated from that number; thus, an overall $6.3 \%$ response rate was achieved. While this percentage is low, it was considered sufficient for the exploratory nature of the study.

In line with previous studies (e.g., Alonso, 2011b; Aylward, 2007), Pearson's chi-square $\left(\chi^{2}\right)$ and Cramer's V statistics were run when establishing potential differences, for instance, regarding involvement in wine tourism and the items provided as answer choices. Regarding respondents' comments, in the following sections these comments are labeled as follows: "Respondent Italy 1" as IT1, "Respondent Spain 1" as S1, "Respondent New World 1" as NW1, and so on.

Table 1

\begin{tabular}{|c|c|c|c|c|}
\hline & $\begin{array}{l}\text { Production } \\
\text { (in Liters) }^{\mathrm{s}}\end{array}$ & Contacted & $\begin{array}{c}\text { Useful } \\
\text { Responses } \\
(\%)\end{array}$ & $\begin{array}{c}\text { Selected } \\
\text { (SMEs) } \\
(\%)\end{array}$ \\
\hline \multicolumn{5}{|l|}{ Old World } \\
\hline Italy (IT) & 4.6 billion & 3,300 & $240(7.3)$ & $212(6.4)$ \\
\hline $\begin{array}{l}\text { Spain (S) } \\
\text { Totals }\end{array}$ & 3.6 billion & 1,700 & $136(8.0)$ & $118(6.9)$ \\
\hline $\begin{array}{c}\text { Totals } \\
\text { New World }\end{array}$ & & 5,000 & $376(7.5)$ & $330(6.6)$ \\
\hline $\begin{array}{l}\text { New World } \\
\text { Australia }\end{array}$ & 1.07 billion & $\begin{array}{l}\text { Totals } \\
\text { New World }\end{array}$ & $30(4$ & 30 \\
\hline New Zealand & 190 million & 490 & $29(5.9)$ & $\begin{array}{l}30(4.7) \\
28(5.7)\end{array}$ \\
\hline United States & 2.7 billion & 459 & $18(3.9)$ & $18(3.9)$ \\
\hline Canada & 56 million & 186 & $17(9.1)$ & $17(9.1)$ \\
\hline Argentina & 1.63 billion & 148 & $12(8.1)$ & $11(7.4)$ \\
\hline South Africa & 922 million & 147 & $7(4.8)$ & $7(4.8)$ \\
\hline Unuguay & 112 million & 60 & $11(18.3)$ & $6(10.0)$ \\
\hline Chile & 884 million & 60 & $8(13.3)$ & $4(6.7)$ \\
\hline Totals & & 2,192 & $132(6.0)$ & $121(5.5)$ \\
\hline Overall totals & & 7,192 & $508(7.1)$ & $451(6$. \\
\hline
\end{tabular}

aFigures are from 2010. Source: Wine Institute (2011). 
Table 2

Demographic Characteristics of Wineries and Their Owners/Managers

\begin{tabular}{|c|c|c|c|c|}
\hline Characteristics & $\begin{array}{c}\text { Italy } \\
{[n(\%)]}\end{array}$ & $\begin{array}{c}\text { Spain } \\
{[n(\%)]}\end{array}$ & $\begin{array}{c}\text { New } \\
\text { World } \\
{[n(\%)]}\end{array}$ & Total \\
\hline \multicolumn{5}{|l|}{ Time since the winery has been established } \\
\hline 15 years or less & $60(28.3)$ & $64(54.2)$ & $86(71.1)$ & $210(46.6)$ \\
\hline $16-35$ years & $49(23.1)$ & $28(23.7)$ & $31(25.6)$ & $108(23.9)$ \\
\hline $36+$ years & $100(47.2)$ & $25(21.2)$ & $3(2.5)$ & $128(28.4)$ \\
\hline Missing & $3(1.4)$ & $1(0.8)$ & $1(0.8)$ & $5(1.1)$ \\
\hline \multicolumn{5}{|l|}{ Role(s) of respondents } \\
\hline Only one role (e.g., owner only) & $147(69.3)$ & $54(45.8)$ & $55(45.5)$ & $256(56.8)$ \\
\hline More than one role (e.g., owner and winemaker) & $57(26.9)$ & $58(49.2)$ & $61(50.4)$ & $176(39.0)$ \\
\hline Missing & $8(3.8)$ & $6(5.1)$ & $5(4.1)$ & $19(4.2)$ \\
\hline \multicolumn{5}{|l|}{ Production of the winery (bottles) } \\
\hline 19,999 and below & $28(13.2)$ & $24(20.3)$ & $52(43.0)$ & $104(23.1)$ \\
\hline $20,000-99,999$ & $110(51.9)$ & $47(39.8)$ & $65(28.9)$ & $192(42.6)$ \\
\hline $100,000+$ & $73(34.4)$ & $46(39.0)$ & $33(27.3)$ & $152(33.7)$ \\
\hline Missing & $1(0.5)$ & $1(0.8)$ & $1(0.8)$ & $3(0.7)$ \\
\hline \multicolumn{5}{|l|}{ Number of employees } \\
\hline 5 or fewer & $156(73.6)$ & $79(66.9)$ & $89(73.6)$ & $324(71.8)$ \\
\hline $\begin{array}{l}\quad 6-30 \\
\text { Involvement in wine tourism }\end{array}$ & $56(26.4)$ & $39(33.1)$ & $32(26.4)$ & $127(28.2)$ \\
\hline \multicolumn{5}{|l|}{ Involvement in wine tourism } \\
\hline Yes & $182(85.8)$ & $92(78.0)$ & $92(76.0)$ & $366(81.2)$ \\
\hline No & $19(9.0)$ & $21(17.8)$ & $21(17.4)$ & $61(13.5)$ \\
\hline Missing & $11(5.2)$ & $5(4.2)$ & $8(6.7)$ & $24(5.3)$ \\
\hline
\end{tabular}

Results

Demographic Results Among the Participating Wineries

Table 2 shows the demographic characteristics of the participating wineries. Almost half of the wineries $(46.6 \%)$ have been established in the last 15 years, while the second largest group (28.4) was established 36 or more years ago. In this study, New World and Spanish wineries belong to the more recently established groups as opposed to Italian wineries, with $47.2 \%$ being established at least 36 years ago. In addition, respondents from Italian wineries tend to fulfill one role only, as opposed to New World and Spain respondents, who tend to occupy multiple roles. The fact that wineries from these last two groups have been established more recently than Italian wineries may be a reason for this finding. In view of their new status, perhaps respondents are compelled to diversify their operations in order to maximize existing resources while minimizing expenses. In contrast, the longer establishment of the participating Italian wineries suggests that respondents from this group tend to focus more on running the business, or in delegating other individuals (i.e., wine makers) to perform specific tasks.

The majority of wineries from Italy and Spain ( $85.3 \%$ and $78.8 \%$, respectively) produce 20,000 bottles $(750 \mathrm{ml})$ or more, while only $56.2 \%$ of New World wineries do so. Commonalities between the wineries included their size in terms of employee numbers, with a higher percentage of Italian and New World wineries employing five or fewer employees. Further, a higher percentage of Italian than New World or Spanish respondents indicated that their wineries were involved in wine tourism. The longer establishment of Italian wineries participating in this study could also be a factor for their stronger involvement with wine tourism, compared to the other two groups.

\section{Importance of Studying One's Consumers and Visitors (CsVs)}

Asked in what ways, if any, respondents studied their CsVs, no significant differences were noticed between the three participating groups (Table 3). Overall, the majority (62.3\%) indicated occasionally talking to CsVs to gather their views about 
Table 3

Extent to Which Wineries "Study" Their Consumers and Visitors (CsVs)"

\begin{tabular}{|c|c|c|c|c|}
\hline Items & $\begin{array}{c}\text { Italy } \\
{[n(\%)]}\end{array}$ & $\begin{array}{c}\text { Spain } \\
{[n(\%)]}\end{array}$ & $\begin{array}{c}\text { New } \\
\text { Worid } \\
{[n(\%)]}\end{array}$ & $\begin{array}{c}\text { Totals } \\
{[n(\%)]^{b}}\end{array}$ \\
\hline $\begin{array}{l}\text { Sometimes we talk to our CsVs, for instance, to gather their views on our wines. } \\
\text { We are interested in learning more about our CsVs } \\
\text { We do not carry out any study about our CsVs at this point. } \\
\text { Sometimes we carry out surveys among our CsVs (for instance, via surveys). } \\
\text { We do not have the means (economic, human, other) to study our CsVs. } \\
\text { We do not have time to study our CsVs. } \\
\text { We do not believe that studying our CsVs is necessary. }\end{array}$ & $\begin{array}{r}134(63.2) \\
87(41.0) \\
65(30.7) \\
39(18.4) \\
19(9.0) \\
12(5.7) \\
7(3.3)\end{array}$ & $\begin{array}{l}77(65.3) \\
47(39.8) \\
45(38.1) \\
20(16.9) \\
18(15.3) \\
7(5.9) \\
1(0.8)\end{array}$ & $\begin{array}{r}70(57.9) \\
54(44.6) \\
36(29.8) \\
15(12.4) \\
8(6.6) \\
6(5.0) \\
1(0.8)\end{array}$ & $\begin{array}{r}281(62.3) \\
188(41.7) \\
146(32.4) \\
74(16.4) \\
45(10.0) \\
25(5.5) \\
9(2.0)\end{array}$ \\
\hline
\end{tabular}

Respondents could provide more than one answer.

bercentages are calculated from 451 respondents.

their wines. As illustrated, almost one third of the winery operators do not study their $\mathrm{CsVs}$, and $16.4 \%$ do not have the means, or time, to do so. However, of importance was the finding that $41.7 \%$ are interested in learning more about their CsVs.

Some differences were found and related to whether the wineries were or were not involved in wine tourism; a summary of these results is shown in Table 4. For instance, the majority $(70.5 \%)$ of the participants involved in wine tourism recognized sometimes "talking" to their visitors, compared to $30.5 \%$ of those wineries not involved in wine tourism; this difference was statistically significant $\left[\chi^{2}(1, n=418)=35.497, p<0.001\right]$. At the same time, $28.1 \%$ of those respondents whose wineries were involved in wine tourism acknowledged not studying their visitors, compared to $67.8 \%$ of those wineries not involved in wine tourism $\left[\chi^{2}(1\right.$, $n=418)=35.661, p<0.001]$. Further, a higher percentage $(46.5 \%)$ of those respondents whose wineries are involved in wine tourism indicated being interested in learning more about their consumers, compared to $28.8 \%$ of those whose wineries were not involved in wine tourism $\left[\chi^{2}(1, n=\right.$ $418)=6.446, p<0.05]$. In the case of wineries involved in wine tourism, this percentage is modest, especially given that such involvement may require regular face-to-face interaction and contact.

Overall, of concern is that almost 3 in 10 wineries involved in wine tourism are not currently studying their visitors; given the low percentage of participants, this number may be much higher. In contrast, and despite only representing $13.5 \%$ of the entire participating population, only 3 out of 10 managers whose wineries are currently not involved in wine tourism appear to be interested in studying CsVs. These findings have significant implications for wine marketing and wine tourism. Earlier research (Alant \& Bruwer, 2004) conducted among 214 winery CsVs identified three dimensions: visitor, wine region, and visit dynamic. Expectedly, the visitor dimension includes demographics and wine consumption; the wine region includes attractions and the regional brand image, while the visit dynamic includes first-time and repeat visit (Alant \& Bruwer, 2004). Further, under these three dimensions, several subdimensions linked to CsVs' motivations also emerged, including wine brand affinity (visitor dimension), infrastructure and accessibility (wine region dimension), and duration of stay, travel mode, and travel party (visit dynamic) (Alant \& Bruwer, 2004).

Together, these dimensions provide a blueprint for wineries' management to not only learn about the visitors, but extend such knowledge to promote and market the region, thus creating a continuous flow of information that goes beyond the wine tourism experience. In fact, Brown and Getz (2005) found that many winery visitors have an interest in visiting and experiencing from classic wine destinations (France, Italy), those close-to-home, and other regions considered of "major growth potential" such as Australia. This finding, and the fact that other wine countries do not seem to have a strong appeal among visitors, led Brown and Getz (2005) to conclude: "marketing and image are also important in differentiating wine tourism destinations" (p. 274). Thus, the apparent modest 
involvement in studying CsVs may be preventing wineries from maximizing potential commercial opportunities, with direct consequences for the successful marketing of the local wine sector and the region.

Similar percentages of participants of both groups (wine tourism involvement or lack of involvement), acknowledged lacking the means (economic, human, other) to study their CsVs. In fact, $10 \%$ of those respondents whose wineries are involved in wine tourism versus $13.6 \%$ of those whose wineries are not involved in wine tourism acknowledged such limitation. A similar outcome (5.8\% vs. $6.8 \%$ ) was noticed when comparing wine tourism involvement or no involvement and the item "We do not have time to study our consumers."

While some of the differences above are partly expected, the overall findings in this section are surprising. Moreover, given the involvement with wine tourism of the large majority of the wineries, studying their visitors could provide many benefits. For example, in referring to other authors (Cronin \& Taylor 1992; Gabbot \& Hogg 1997, Gwynne, Devlin, \& Ennew, 1998), O'Neill et al., 2002 explain that "understanding the current awareness of service quality and its importance to cellar door sales is essential" (p. 344). However, this notion does not apply to many of the participating wineries, and is in stark contrast to the "message" of contemporary consumer and wine tourism research that emphasizes the importance of studying one's CsVs.

Further analysis identified that $77.7 \%$ of respondents, whose wineries were established between 16 and 35 years ago, indicated sometimes talking to their visitors and gathering their views, compared to $60.4 \%$ of those whose wineries were established in the last 15 years or earlier $\left[\chi^{2}(2, n=428)=\right.$ $10.297, p<0.05]$. This finding suggests that the more experience running the winery respondents have, the more inquisitive they are about how their products are perceived. Wine production levels also appeared to influence wineries' involvement in studying their CsVs. For example, $10.3 \%$ of those producing fewer than 20,000 liters of wine indicated "Sometimes we carry out surveys among our CsVs (for instance, via questionnaires)," as opposed to $25.9 \%$ of those producing 100,000 liters and more $\left[\chi^{2}(2, n=431)=12.402, p<0.05\right]$. While statistically significant, the very low percentages of this last finding reinforce the argument that despite its potential benefits, there is a very limited level of enquiry among the participating wineries about winery visitors or about their experience.

\section{Respondents' Comments}

As few as 58 respondents (12.8\%) provided written comments; this modest involvement is in part illustrative of the of wineries' limited interest and

Table 4

Summary of Comparisons Using Pearson's Chi-Square $\left(\chi^{2}\right)$ Test

Comparison between involvement and lack of involvement in wine tourism and extent to which respondents "study" their CsVs

$70.5 \%$ of participants involved in wine tourism acknowledged sometimes "talking" to their $\mathrm{CsVs}$, as opposed to only $30.5 \%$ of those not involved in wine tourism.

$28.1 \%$ of respondents involved in wine tourism do not carry out any study about their CsVs at this point, compared to $67.8 \%$ of those not involved in wine tourism.

$46.5 \%$ of respondents involved in wine tourism are interested in leaming more about their $\mathrm{CsVs}$ as opposed to $28.8 \%$ of those not involved in wine tourism.

Comparison between time since the winery was established and extent to which respondents "study" their CsVs

$77.7 \%$ of respondents whose wineries were established between $16-35$ years ago acknowledged sometimes "talking" to their CsVs, as opposed to only $60.4 \%$ of those whose wineries were established 15 years ago or less.

Comparison between wine production volume and extent to which respondents "study" their CsVs

$25.9 \%$ of respondents whose wineries produce 100,000 liters of wine or more sometimes study their CsVs through surveys, as opposed to $10.3 \%$ of those whose wineries produce 20,000 liters or less.

$\begin{array}{lll}35.497 & 1 & p<0.001 \\ 35.661 & 1 & p<0.001 \\ 6.446 & 1 & p<0.05\end{array}$

$10.2972 \quad p<0.05$

$12.402 \quad 2 \quad p<0.05$ 
commitment to studying their visitors (Table 3). A clear difference was found among the participating groups. For example, despite representing only $26.8 \%$ of the entire sample of participants, just over half $(30,51.7 \%)$ of the comments were made by New World respondents. In a way, this finding suggests more familiarity - and involvement-in some of the New World countries and regions with the wine tourism concept among winery entrepreneurs. This aspect also mirrors the large number of wine tourism studies conducted in New World wine regions in the last decades. In contrast, recent studies (López-Guzmán et al., 2011; Marzo-Navarro \& Pedraja-Iglesias, 2012) suggest the developing nature of wine tourism in some Old World countries and regions, in this case Spain.

The Skeptical, Passive, and (Over)Confident Winery Manager: In general, the comments that respondents provided identified two distinct respondent groups. The views of the first group $(17,29.3 \%)$ were skeptical, passive in their involvement, or overconfident regarding the importance of studying CsVs. Interestingly, 15 of these participants had originally indicated that their wineries were involved in wine tourism. One respondent from this group flatly dismissed the need for studying CsVs: "I am a local [resident]; I believe I know our direct consumers well enough" (RS1). This sentiment was echoed by other respondents whose wineries were involved in wine tourism. These respondents did not perceive a value in studying their CsVs, or they were skeptical of doing so:

We know our visitors perfectly; we keep their email contacts to communicate with them. (RI1)

We have feedback sheets, guest book, and focus groups. We understand our customers very well. (NW1)

By selling directly we have a continuous relationship with our clients and therefore we don't see it necessary to conduct a market study. (RI2)

We assume that, given the importance of our area, consumers' knowledge is quiteadvanced. ... (RI3)

People do not want to fill out questionnaires. (RS2)

So far we do not have any method in place for tracking our customers that come through the cellar door... . We do get a good idea just from talking to them across the counter. (NW2)
Other Categories of Winery Owners and Managers. A second group of respondents (41, $70.7 \%$ ) reflected on the necessity to understand and talk to their CsVs. Importantly, this information gathering process was valuable and, despite the limitations of their businesses in terms of size, human or financial resources, respondents seek to study or communicate with CsVs and learn about them, as the following comments illustrate:

We ALWAYS talk to our visitors-it's about all we can do currently, but appreciate the value that more formal studies might have." (NW3)

We believe that one of the key aspects is to get to know our potential clients. (NW4)

Another respondent acknowledged that "no formal study or survey mechanisms" (NW5) existed at the winery; in this situation, "customer cellar door staff interaction" was the main source of information for the winery. Although these approaches were important, and respondents were interested in their consumers' feedback, tastes, and preferences, the approach to studying their CsVs was not strategic. Indeed, despite the value of understanding their consumers' preferences and encouraging feedback relevant to their winery experiences, operators had not developed systems and processes to respond to the information gathered.

In one case, the comments suggested that the study of one's CsVs was almost an obsessive exercise:

We "bombard" them with requests to broaden our knowledge about their consumption habits. (RI4)

Also, only one respondent indicated printing a winery newsletter to study the winery's CsVs, while a second acknowledged using social media (i.e., Facebook) for this purpose. Similarly, very few comments alluded at the use of technology, or the compilation of a visitor database or plans to do so:

We ask our clients to send us a message, evaluating their visit and our wines. (RS2)

Building up databases of clients. (NW7)

Our POS (point of sale) accepts zip/postal codes with each transaction, which help us determine where are customers are coming from. (NW8)

We collect voluntary zip code info and track distance based on that. (NW9) 
Most comments mentioned the use of traditional approaches to gathering information about their $\mathrm{CsVs}$, including point of sale surveys, visitor books, and qualitative employee-driven observations:

We have a registry of our visits so that we learn about their profile (age, gender/sex, origin, whether traveling in couples or groups). (RS3)

All our visitors complete a questionnaire and write their impressions in a record book. We keep their contact details, [when we are] promoting events, new products, etc. (RI5)

We are preparing a survey because we are interested to know what consumers think of us, how they learned about us and for them to make suggestions to help us improve. (RS4)

We count the numbers of visitors to our winery; we have a "golden" book, and also space for complaints. (NW10)

We track the amount of people that come through our door, how they heard about our business, and how much they spend. (NW11)

Running Pearson's chi-square and Cramer's V statistics to test whether the two seemingly different groups in terms of their approach to studying CsVs were related to the age of the winery, respondents' number of roles, the winery's volume of production, or number of employees, no statistically significant differences were identified.

\section{Perceived Benefits of Studying and Learning From CsVs}

Overall, respondents' comments suggest the different ways in which they were benefitting or how they perceived and interpreted the benefits of studying their CsVs. For instance, one winery owner who marketed and sold his wines at a local farmers' market perceived that studying and understanding his consumers' needs and wants had a direct impact on the final wine product:

The communication with the customer is all important, so is the tasting of the wine before any purchase. I understand the likes and preferences; do a lot of educating; all this influences my winemaking. (NW12)

While respondents were interested in feedback that would advance their knowledge: "It is quite positive knowing what visitors think of our winery" (NW10), learning from consumers was clearly not only about the positive aspects of the wine(s) or the winery experience: "we encourage and welcome feedback on our wines, even negative feedback" (NW13). Face-to-face encounters and conversations were useful for visitors to absorb information about the winery's products, and learn how to make more informed decisions about wines:

We speak with our customers and learn a lot about the market, preferences, etc. (NW14)

We always talk to our visitors as their tasting notes assist us greatly. (NW15)

During their visit we chat with them (visitors) to know their tastes, preferences, and opinions... we taste wines jointly so that they become active participants and learn as much as possible. (RS5)

"Active participation" in some cases was not limited to encouraging visitors to learn information about the winery, or its wines, but extended to promoting the region or other tourist attractions:

We also actively promote other tourist attractions, including other vineyards and wineries. (NW13)

We talk to our guests (not all of whom are necessarily interested in wine) about agri-tourism, and with tourists ... that arrive directly to our winery to buy wines. (RII6)

This last comment is in line with research by Alant and Bruwer (2004) and Brown and Getz (2005), who similarly discuss the (leisure) opportunities wine regions might provide in spite of the fact that they may not necessarily be linked to wineries and the wine product. Consequently, wine tourism and winery operators' activities can benefit the rural communities in which they reside. This multiplier effect is of notable importance given the economic and other hardships experienced by many regional and rural communities.

Respondents' views also illustrate the strategies being developed amongst winery operators to build and retain market share:

We try to gain visitors' loyalty. ... Those staying more than four nights at our accommodation "receive a three-year gift": one of our vines they 
can come back to, work with, and follow its development. Each year, these visitors will receive one personalised bottle of wine (with a customised label), and at their request, they can also receive a photo of their vine in its various phenological cycles [dormant, budburst, flowering, etc.]. (RI7)

This respondent was implementing a knowledgebased initiative in order to build long-term wineryvisitor relationships. Moreover, through the visitors' interest in wine, and by being awarded a symbolic 3-year gift, these visitors had an opportunity to build an emotional association and in turn a sense of attachment with the place they visited and the wines they consumed. For the winery, this initiative also provided an avenue to "test" visitors" response and build more knowledge in the process.

\section{Discussion, Conclusions, Implications, Recommendations, and Future Research}

Given its identified importance for the success of many product- and service-orientated businesses, learning about $\mathrm{CsVs}$ in the context of the wine tourism experience has been a key emphasis in much of the contemporary wine tourism literature. For example, "As the market for wine develops so the wine tourism experience also changes" (Ali-Knight \& Charters, 1999, p. 10). If winery operators do not see a value in studying and understanding their current consumers, then their cellar door offerings may not align with changing consumer expectations. In light of emergent market challenges, "Wineries must grow with the demand to give people the experience they are looking for" (Ali-Knight \& Charters, 1999, p. 11). Therefore, studying CsVs may allow many wineries to identify and anticipate challenges, trends, and better address consumer and visitor needs and wants. However, while much of the existing research has examined the demand (CsVs) side of wine tourism, very few studies have been conducted on the supply side, that is: from the perspective of winery owners and managers.

The present study examined this underresearched area from the perspective of a group of Italian, Spanish, and New World micro, small, and medium wineries. Figure 2 provides a conceptual framework of the underlying themes and comments identified in the study's findings. These outcomes confirm very different levels of perceptions, strategies, and initiatives concerning the study of winery
CsVs. In fact, there is an identified disparity between the attitudes and interpretations of winery operators and the normative "message" provided by many researchers regarding the importance of knowing about one's consumers, and how such knowledge can benefit wineries (see Fig. 1). Further, while respondents overall acknowledge being involved in studying their CsVs, one in three are not directly engaging in any such initiatives, and over $40 \%$ would like to learn more, clearly suggesting a deficiency among the participating wineries in learning their CsVs. Thus, an argument can be made that there appears to be a gap between the emphasis placed in contemporary wine and wine tourism research, that is: what wineries "should or could be doing," and what in actual fact is occuuring among the participating winery owners and managers.

Respondents' comments also illustrate a certain level of "fragmentation" in their perceptions and involvement in such efforts; the study identified that one group, the majority, is keen to expand the knowledge of CsVs. Indeed, members of this group are reaching out to their CsVs in different ways to study them, and potentially benefit from the information. In contrast, a second, smaller group is composed of skeptical, passive, and seemingly overconfident respondents, some of whom downplayed the importance of consumer and visitor study initiatives. No associations, however, were noted between these two groups and other characteristics of wineries and respondents, including age of the winery, volume of production, number of employees, or whether respondents have one or more roles at the winery.

Hence, the seeming lack of consensus illustrates that, despite contemporary issues in the wine sector, many winery owners and managers remain oblivious, or simply are unable to become more involved in learning about their CsVs. Contemporary issues include not only fierce competition between wines from already established and emerging wine producers and markets, but also developments from the consumer side, with potential implications for wine tourism. For instance, in South Australia alone, Bruwer and Li (2007) recognized five different wine-related lifestyle (WRL) segments among wine consumers: 1) conservative, knowledgeable, 2) enjoyment orientated, social, 3) basic, 4) mature, time-rich, and 5) young 


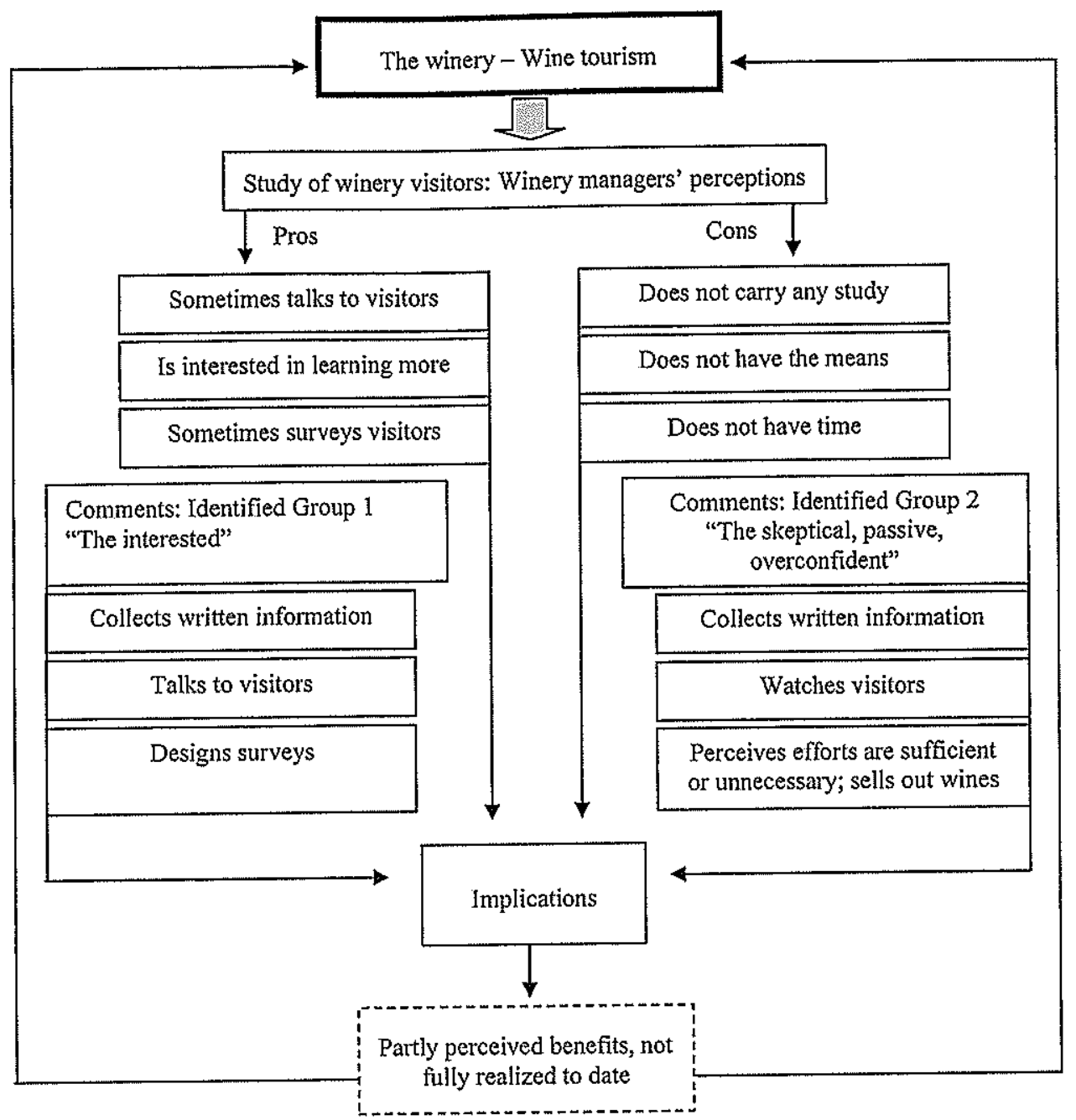

Figure 2. A conceptual construct of the study's overall findings.

professional. Another study conducted among US households (Kolyesnikova, Dodd, \& Duhan, 2008) segmented respondents into four clusters: local enthusiasts, local detractors, local advocates, and local nonadvocates. These are only two among many different illustrations of wine, tourism, and wine tourism consumer segmentation studies. With the continuous growth of wine brands, tourist destinations, and segmentation of consumer markets, the overall findings illustrate a rather modest involvement among wineries to address these very important developments.

One argument for participants' lack of research may be due to the limited size and resources of most participating wineries. However, given the potential benefits to be gained from learning about one's consumer and visitor, the existing opportunities from this learning process should not be undervalued. Regarding this aspect, as industries move to more customized and less mass marketing consumer learning experiences, many opportunities exist for framing aspects related to consumers' direct experiences (LaTour et al., 2011). Indeed, wineries and wine tourism feature many components, and a potentially ideal environment for service, even product customization. As noted previously, one comment (NW13) indicated how winery and consumer interaction at a farmers' market was impacting the respondent's final wine product. 
The overall findings have very important implications for wineries' management, for wine regions, wine tourism, and even for peripheral areas that are tourist destinations in their own right. For example, the identified modest involvement in studying one's CsVs may result in lack of knowledge about one's CsVs. This deficiency may act to prevent organizational innovation and creativity, as well as unrealized and potential business opportunities. Moreover, a winery that is failing to provide a consistent product and service quality may inevitably affect the image of the surrounding wineries, the entire wine region, or even the rural destination. In turn, if many wineries are failing, the negative consequences will be much stronger. These potential consequences may also have clear implications for the wine tourism product in the wine region.

While many wineries lack the resources to invest in external assistance to study and learn about their $\mathrm{CsVs}$, several basic and economically feasible steps could be implemented. For instance, as some responses demonstrate, written feedback ("golden book"), postvisit feedback, or simple face-to-face communication can provide valuable knowledge to winery owners and managers. Further, few wineries were utilizing nontraditional strategies such as social media to both learn about and market their products and services. This finding is surprising in view of changing consumer preferences and in light of the need to retain and build market share. Another aspect that only one respondent in this study mentioned refers to the potential involvement of students in gathering consumer and visitor feedback, for instance, as part of a university postgraduate project. While an argument could be made about the role of universities or their programs in providing "free" consulting to businesses, allowing university students to gain in-the-field or practical experience in their areas of study by utilizing those skills (e.g., quantitative, analytical) could be of significant value for them as a learning process, and for wineries.

The number of participating wineries represents a limitation in this study. Consequently, it is acknowledged that the research findings are not generalizable and cannot be applied to other, micro, small, and medium size winery owners and managers, about wine tourism or about the wine industry of the participating countries. In addition, the number of participants in the different groups is not balanced, with Italy's respondent group being clearly the more predominant, while other countries are clearly underrepresented.

However, the study provides initial insights into an area of critical importance: that of product and service delivery and the wine tourism experience. As discussed, the supply side of wine tourism remains underresearched, particularly from the perspective of winery owners and managers. The study's findings also provide a foundation for future research. Future research could gather insights from a much larger number of participants, and also investigate whether differences exist in terms of country, region, or even DOs. In doing so, findings could help identify which of these, if any, tend to be more involved in studying their visitors, reasons for and strategies in such involvement, and benefits they might be obtaining by being more highly involved in such efforts.

Using a larger participant sample, studies could also determine whether differences exist between Old World and New World wineries and the extent to which winery owners and managers of these two wine "worlds" engage in studying their CsVs. Future investigations could also make comparisons between wineries according to their size (e.g., micro and small vs. medium) to identify whether size is a factor for wineries to engage in studying their CsVs. Finally, there is scope to further investigate the winery visitor (demand side), to make comparisons between visitors and different sizes of wineries, or between Old World and New World wineries. All these efforts could significantly contribute to increased knowledge, with practical applications for wine tourism practitioners (wineries) and academics. Such knowledge could also assist wine regions in their efforts to developing wine tourism, and in providing more memorable winery experiences, in the process enhancing the image of the wine region.

\section{References}

Alant, K., \& Bruwer, J. (2004). Wine tourism behaviour in the context of a motivational framework for wine regions and cellar doors. Joumal of Wine Research, 15(1), 27-37.

Ali-Knight, J., \& Charters, S. (1999). Education in a West Australian wine tourism context. International Journal of Wine Marketing, 11(1), 7-18.

Alonso, A. D. (2011a). The red-headed stepchild of wine? Marketing muscadine wines in the Southern USA. British Food Joumal, I13(10), 1290-1304. 
Alonso, A. D. (2011b). Internationalisation of small and medium New Zealand wineries: An exploratory study. SEAANZ Jounal, 17(1), 58-73.

Alonso, A. D., \& Liu, Y. (2011). The potential for marrying local gastronomy and wine: The case of the 'fortunate islands.' International Journal of Hospitality Management, 30, 974-981.

Asero, V., \& Patti, S. (2011). Wine tourism experience and consumer behaviour: The case of Sicily. Tourism Analysis, I6(4), 443-460.

Australian Bureau of Statistics. (2001). Small business in Australia, 2001. Retrieved November 3, 2011, from http://www.abs.gov.au/AUSSTATS/abs@.nsf/Lookup/ 1321.0Main+Features 12001? OpenDocument

Aylward, D. (2007). Innovation an inertia: The emerging dislocation of imperatives within the Australian wine industry. International Journal of Technology and Globalisation, 3(2/3), 246-262.

Brown, G., \& Getz, D. (2005). Linking wine preferences to the choice of wine tourism destinations. Journal of Travel Research, 43(3), 266-276.

Bruwer, J. (2003). South African wine routes: some perspectives on the wine tourism industry's structural dimensions and wine tourism product. Tourism Management, 24(4), 423-435.

Bruwer, J., Lesschaeve, I., \& Campbell, B. L. (2012). Consumption dynamics and demographics of Canadian wine consumers: Retailing insights from the tasting room channel. Journal of Retailing and Consumer Services, 19(1), 45-58.

Bruwer, J., \& Li, E. (2007). Wine-related lifestyle (WRL) market segmentation: Demographic and behavioural factors. Journal of Wine Research, 18(1), 19-34.

Carlsen, J. (2004). A review of global wine tourism research. Jounnal of Wine Research, 15(1), 5-13.

Charters, S., \& Ali-Knight, J. (2002). Who is the wine tourist? Tourism Management, 23(3), 311-319.

Cronin, J. J., \& Taylor, S. A. (1992). Measuring service quality: a re-examination and extension. Joumal of Marketing, 56(3), 55-68.

Dodd, T. (1995). Opportunities and pitfalls of tourism in a developing wine industry. International Joumal of Wine Marketing, 7(1), 5-16.

European Commission. (2010). Small and medium-sized enterprises (SMEs). Retrieved November 12, 2011, from http://ec.europa.eu/enterprise/policies/sme/facts-figuresanalysis/index_en.htm

Gabbot, M., \& Hogg, G. (1997). Contemporary services marketing management: $A$ reader. London,: The Dryden Press.

Getz, D., \& Brown, G. (2006). Critical success for wine tourism regions: a demand analysis. Tourism Management, 27(1), 146-158.

Gill, D., Byslma, B., \& Ouschan, R. (2007). Customer perceived value in a cellar door visit: the impact on behavioural intentions. International Journal of Wine Business Research, 19(4), 257-275.

Gluckman, R. L. (1986). A consumer approach to branded wines. European Journal of Marketing, 20(6), 27-44.

Gwynne, A. L., Devlin, J., \& Ennew, C. T. (1998). Service quality and customer satisfaction: A longitudinal analysis (pp. 186-191). The British Academy of Marketing Annual Conference, Sheffield Hallam University, Sheffield, July 8-10.

Hall, C. M., Sharples, L., Camboume, B., \& Macionis, N. (2000). Wine tourism around the world: Development, management and markets. Burlington, MA: Butterworth-Heinemann.

Kolyesnikova, N., Dodd, T., \& Duhan, D.F. (2008). Consumer attitudes towards local wines in an emerging region: a segmentation approach. International Journal of Wine Business Research, 20(4), 321-334.

LaTour, K. A., LaTour, M. S., \& Feinstein, A. H. (2011). The effects of perceptual and conceptual training on novice wine drinkers' development. Comell Hospitality Quarterly, 52(4), 445-457.

López-Guzmán, T., Rodriguez-García, J., SánchezCañizares, S., \& Luján-García, M. (2011). The development of wine tourism in Spain. International Journal of Wine Business Research, 23(4), 374-386.

Macionis, N., \& Cambourne, B. (1998). Wine tourism: Just what is it all about? Australian and New Zealand Wine Industry Jounal, 13(1), 41-47.

Marzo-Navarro, M., \& Pedraja-Iglesias, M. (2012). Critical factors of wine tourism: Incentives and barriers from the potential tourist's perspective. International Joumal of Contemporary Hospitality Management, 24(2), 312-334.

Ministry of Economic Development. (2005). Defining small and medium-sized enterprises. Retrieved November 7, 2011, from http://www.med.govt.nz/templates/Multipage DocumentPage_2814.aspx

O'Neill, M., \& Charters, S. (2000). Service quality at the cellar door: Implications for Westen Australia's developing wine tourism industry. Managing Service Quality, $10(2), 112-122$.

O'Neill, M., \& Palmer, A. (2004). Wine production and tourism: Adding service to a perfect partnership. Cornell Hotel and Restaurant Administration Quarterly, 45(3), 269-284.

O'Neill, M., Palmer, A., \& Charters, S. (2002). Wine production as a service experience--The effects of service quality on wine sales. Jomnal of Services Marketing, I6(4), 342-362.

Ryan, C. (2002). The towrist experience ( 2 nd ed.). London: Thomson.

Scherrer, P., Alonso, A. D., \& Sheridan, L. (2009). Expanding destination image: Wine tourism in the 'Canaries.' International Journal of Tourism Research, $11(5), 451-463$.

Tassiopoulos, D., Nuntsu, N., \& Haydam, N. (2004). Wine tourists in South Africa: A demographic and psychographic study. Journal of Wine Research, 15(1), 51-63.

Williams, P. (2001). Positioning wine tourism destination: An image analysis. International Journal of Wine Marketing, 13(3), 42--58.

Wine Institute. (2011). World wine production by country (2007-2010). Retrieved October 19, 2012, from http:// www.wineinstitute.org/files/2010_World_Wine_Pro duction_by_Country.pdf 